\title{
PSYCHIATRIC MORBIDITY OF SUICIDE ATTEMPT PATIENTS REQUIRING ICU INTERVENTION
}

\author{
MMA SHALAHUDDIN QUSAR ${ }^{1}$, NAHID MAHJABIN MORSHED ${ }^{1}$, MD ABDUL KADER ${ }^{2}$, MD ABUL KALAM \\ AZAD $^{3}$, MD ALAL UDDIN ${ }^{4}$, MUHAMMAD ABDUL KAYUMSHAIKH $^{5}$
}

\begin{abstract}
This study was carried out in a private Intensive Care Unit (ICU) to assess the psychiatric morbidities and major psychiatric problems in patients requiring ICU. The most common psychiatric diagnosis was found to be Depressive disorder followed by attention seeking behavior. Chemicals (organophosphorous, kerosene and other medicine) were the most frequent agent used among suicide attempt patients.
\end{abstract}

Keyword: Deliberate self harm, intensive care, mood disorders

\section{Introduction}

Suicide is a tragic and serious preventable public health problem all over the world. ${ }^{1-3}$ It is one of the three leading causes of death among 15-44-year old people globally. ${ }^{4}$ Suicide rates among young people appear to be rising in both developed and developing countries more quickly. In recent times adolescent suicides have been on the increase. ${ }^{1,4-6}$ Like adults, the number of adolescents who committed suicide has been increasing in Japan also. ${ }^{7}$

Suicide is the human act of self inflicting, self intentioned cessation, committed out of constricted thinking, tunneled logic and acute anguish. Attempted suicide is defined as a potentially self injurious action with a non-fatal outcome for which there is evidence, either explicit or implicit that the individual intended to kill himself or herself. The action may or may not result in injuries. ${ }^{8}$

Population-based surveillance in a rural community in southwest Bangladesh revealed that suicide is a major cause of mortality, especially in young females. Mortality from suicide occurred at a rate of 39.6 per 100,000 populations per year from 1983-2002. Among young people, 10-19 years old, suicide accounted for
$42 \%$ of deaths; $89 \%$ of suicide-associated deaths in this age group were in females. Suicide-associated death rates from this surveillance area are substantially higher than rates reported elsewhere in Asia, warranting further studies aimed at identifying risk factors for suicide and strategies for prevention. ${ }^{9}$

Prevalence study in India showed between $4-12 \%$ of the general population have made at least one attempt and the repetition rate (persons who attempt suicide again) is $50 \% .^{10,11}$

According to National Crime Records Bureau of India it was seen that in every 5 minutes a person commits suicide, 7 attempts to kill themselves forming about 100,000 suicide death per year in India. ${ }^{12}$ According to the report of the Government of India it was found that that the suicide rate is highest in the State of Kerala, ninth year in a row, when compared to other states in India. ${ }^{11,13}$

Financial difficulties, psychosocial problems, failure in exams, defamation are the major stressors that lead to suicide in males. Females found harassment, family problems, diseases, unemployment etc. as the major stressors that they were forced to attempt

1. Associate Professor, Department of Psychiatry, Bangabandhu Sheikh Mujib Medical University (BSMMU).

2. Assistant Professor, Department of Medicine, BSMMU.

3. Associate Professor, Department of Medicine, BSMMU.

4. HMO, ICU, Dhaka Medical College Hospital

5. FCPS Course Student, BSMMU.

Correspondence: Dr. MMA Shalahuddin Qusar, Associate Professor, Department of Psychiatry, Bangabandhu Sheikh Mujib Medical University (BSMMU), Dhaka, Bangladesh 
suicide. ${ }^{13}$ Low frustration tolerance, problems in education system, parenting attitudes, weakening protective values of social institutions like family, increased use of alcohol all contributes to the stressor ultimately leading to suicide.

Biological studies suggest that low serotoninergic activity is associated with suicidal behavior. Data from work with monozygotic and dizygotic twins indicate that the clustering of suicide in a family may represent a genetic predisposition to the psychiatric disorders that are associated with suicide. ${ }^{10}$

\section{Materials and Methods}

This is a cross-sectional study which was carried out in an Intensive Care Unit (ICU) set up of a private hospital of Dhaka City. The study was carried out from July 2008 to December 2008 . The patients who died after reaching to ICU following attempted suicide were excluded from the study. The hospital encourages psychiatric evaluation of all attempted suicide cases before discharge. Only those who agreed for psychiatric evaluation were included in the study.

A detailed clinical interview of each patient was taken after the initial problems have subsided. Consultant psychiatrists did the psychiatric assessment and a psychiatric diagnosis done by the DSM-IV where possible. On the other hand, the psychological symptom, which drew sufficient clinical attention, was also included in psychiatric problem list. The information regarding pre-morbid personality and illness was crosschecked with a close relative or a reliable informant. The present study included 44 cases of attempted suicide patients.

\section{Result}

The cross-sectional study which was conducted during the six months period in an ICU set up among 44 patients of attempted suicide throws light on the fact that about $77.3 \%$ patients having a problems of psychiatric disorder or at least a problem which required further attention.

Table I

Age distribution of the suicide attempted patients

\begin{tabular}{lcc}
\hline Different age level & Frequency & Percent \\
\hline Up to 20 & 19 & 43.2 \\
21 to 30 & 14 & 31.8 \\
31 and above & 11 & 25.0 \\
\hline Total & 44 & 100.0 \\
\hline
\end{tabular}

The age of the subjects ranged from 14 to 65 years. Maximum 43.2\% was from age group up to 20. Second most (31.8\%) was from age group 21 to 30 years (Table I).

Table II

Distribution of suicide attempters by current psychiatric illness

\begin{tabular}{lcc}
\hline Psychiatric problems present & Frequency & Percent \\
\hline Yes & 34 & 77.3 \\
No & 10 & 22.7 \\
\hline Total & 44 & 100.0 \\
\hline
\end{tabular}

Table II shows the current psychiatric morbidities or problems. Out of 44 patients 34 (77.3\%) had psychiatric diseases and $10(22.7 \%)$ had no psychiatric problems of clinical attention.

Table III

Distribution of sex and method used by the suicidal attempters

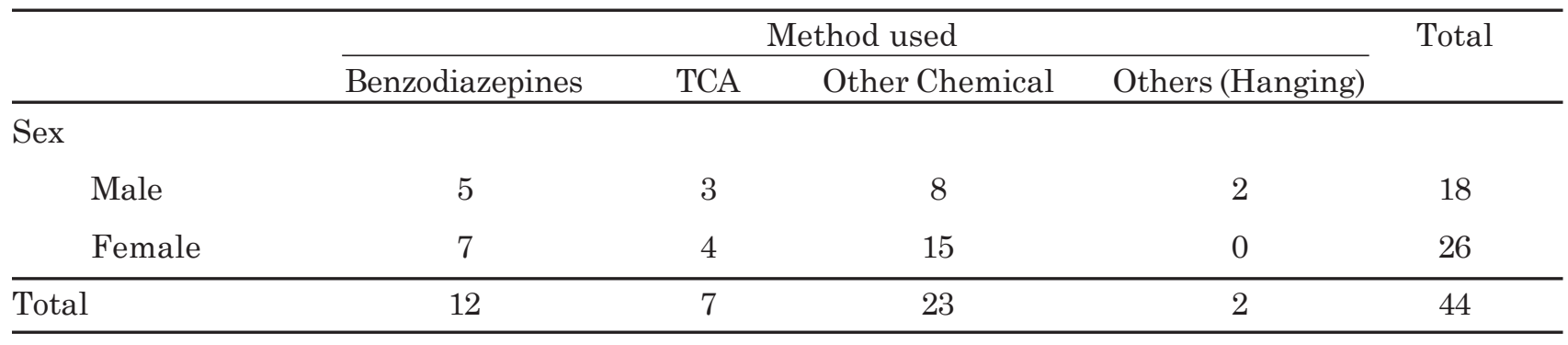


In the table III, it was seen that total number of female attempters was more (26) than male (18).

In terms of method used by the attempters benzodiazepines use was 12, TCA was 7 and others chemicals (like organophosphorous, kerosene, harpic and other medicine) were 23 . On the other hand 2 male used physical methods like hanging.

Table IV

Distribution of response by previous attempts of suicide

\begin{tabular}{cccc}
\hline \multicolumn{2}{l}{ Valid } & & \multicolumn{2}{c}{ History of previous attempts } \\
& & Frequency & Percent \\
\hline \multirow{2}{*}{ No } & 29 & 65.9 \\
& Yes & 15 & 34.1 \\
\hline Total & 44 & 100.0 \\
\hline
\end{tabular}

In the table it was shown that out of 44 patients 29 (65.9\%) has got no history of previous attempts of suicide. However, noticeable number of patients 15 (34.1\%) has previous experience of suicidal attempts previously.

\section{Table V}

Distribution of patients by pattern of current psychiatric problems

\begin{tabular}{llcc}
\hline $\begin{array}{l}\text { Psychiatric disorders } \\
\text { or Problems }\end{array}$ & Frequency & Percent \\
\hline Valid & Depression & 11 & 25.0 \\
& No Diagnosis & 10 & 22.7 \\
Attention Seek & 7 & 15.9 \\
PD/ conduct & 4 & 9.1 \\
Schizophrenia & 3 & 6.8 \\
OCD & 2 & 4.5 \\
Substance abuse & 2 & 4.5 \\
Stress & 2 & 4.5 \\
Sexual dysfunction & 1 & 2.3 \\
Migraine & 1 & 2.3 \\
Psychotic & 1 & 2.3 \\
\hline Total & 44 & 100.0 \\
\hline
\end{tabular}

Out of 44 patients 10 (22.7\%) persons was not diagnosed with any of the psychiatric disorders. Rest $34(77.3 \%)$ was diagnosed with having psychiatric disease or problems. Maximum were 11 (25\%) diagnosed as depressive disorder, followed by attention seeking behavior (Table V). Though attention seeking is not a diagnostic entity by DSMIV but it has got sufficient clinical attention. Other causes include personality disorder or conduct disorder 4 (9.1\%), schizophrenia 3 (6.8\%), OCD and substance abuse 2 (4.5\%).

\section{Discussion}

The cross sectional study has got some limitations itself. The study sample does not represent the picture of whole country but is a very important clue to understand about the psychiatric and psychological status of patients who attempted for suicide by using different methods.

In this study, $43.2 \%$ (19) patients belonged to the age group up to 20 years, which was comparable to other studies done in Kerala, India. On that study it was found that $45.6 \%(\mathrm{n}=94)$ patients belonged to the age group 15 to 34 years. ${ }^{14}$ On the other hand age more than 31 was only $25 \%$ in the current study. It reveals that suicide rates among young people appear to be rising in both developed and developing countries more quickly than all other age groups. In recent times adolescent suicides have been on the increase $^{1}$. Exams, peer pressure and emotional issues are said to be the triggers ${ }^{6}$. If the young generation of day has already run out of hope, the challenge lies in the hands of the adult society to make them realize that life is worth living. ${ }^{1}$

In the present study males constituted $40.9 \%$ (18) of the total sample and females $59.1 \%$. Comparing these figures with the number of completed suicide cases that underwent medico legal autopsy at the Forensic Department Academy of Medical Science, Kannur, Kerala, India, it was found that males constituted $66 \%(n=245)$ and females $34 \%(n=135)$ of the completed suicide group during the same time period. ${ }^{15}$ Which means in the current study for attempted suicide the male female ratio in reversed than that of India study. It means female are more vulnerable for committing suicide than India. This notion also supprted by a study conducted by ICDDR,B in Bangladesh, they found that $89 \%$ of suicide-associated deaths in this age group were in females. ${ }^{9}$ 
In this current study the method used for suicide was divided into four groups. Most of the time the attempters, after recovery from the initial physical problems, do not want to explore the actual name of the chemical or the medicine they used for doing this. Most common name was benzodiazepines, 12 out of 44. On the other hand different chemical including other medicine and chemical was 23.7 person took TCA and 2 man wanted commit suicide by hanging. This picture was a bit different from some study done in India. Where it was found that organo-phosphorus and organo-carbamate poisoning was the most frequent method used by patients to attempt suicide and it was supported by other studies from India. ${ }^{16,17}$ This is explained by the easy availability of insecticides and pesticides in most households.

Another important finding of this study was the previous attempt of suicide. In this current study it was seen that $31.1 \%$ patients has got previous history of attempted suicide which indicates that one attempt further increases the risk of future suicide attempts.

Among the different diagnosis and problems maximum were 11 (25\%) diagnosed as depressive disorder. Untreated depressive disorder is always dangerous. Most of the time these problems are misdiagnosed or under diagnosed in country like Bangladesh. Thus sufferings of the patients increase with time and severity. Depression followed by attention seeking behavior. Though attention seeking is not a diagnostic entity by DSM-IV but it has got sufficient clinical importance.

Prevention of suicide, while potentially effective, is challenging, requiring multifaceted approaches and adaptation of strategies to locally relevant cultural factors. ${ }^{18}$

\section{Conclusion}

Suicide is a complex, long-term outcome that requires complex theoretical models for appropriate study and complex interventions for effective prevention. The highest likelihood of success in saving lives in the long run lies in well designed, comprehensive programs focused on prevention, identification and appropriate treatment of mental and addictive disorders particularly in primary care. ${ }^{3,6}$ This could be facilitated by Continuing education for health care professional to identify and treat Mental illness and by making Psychiatric consultation mandatory for all patients admitted following attempted suicide. ${ }^{16}$ Further studies will be needed to more closely examine underlying factors responsible for suicide and characteristics predictive of suicidal death, and to identify opportunities for contact with a physician or mental health services before suicide is contemplated or attempted. ${ }^{18}$ At the policy and public health level, increased restrictions on access to most commonly used lethal methods of suicide especially insecticides (organophosphorus and organo-carbamate compounds) and prescription medications and improving control of facilitatory factors such as alcohol, influencing the media in their portrayal of suicide and reporting of method may contribute to a reduction in suicide rates. ${ }^{19}$

\section{References}

1. WHO. The World Health Report 1999.

2. World Health Organization. Background of SUPRE. Prevention of Suicide Behaviours - a task for all. Available at: http://www.who.int/mental_health/ prevention/suicide/background/en/

3. Nierenberg AA, Gray SM, Grandin LD. Mood disorders and suicide. J Clin Psychiatry 2001; 62 (suppl 25):21-30.

4. Venkoba Rao A, Kuruvilla K. Psychiatry. New Delhi: B.I.Churchill Livingstone,1998: 160-167

5. World Health Organization. The World Health Report 1995- Bridging the gaps. World Health Organization, Geneva, 1995:17

6. Eddleston M, Rezvi SMH, Keith H, Deliberate Self Harm in Srilanka: anoverlooked tragedy in the developing world. British Medical J 1998;7151:133135.

7. Satomi M, Shuji H, Hitosh K, et al. Clinical Characteristics of Serious Japanese Adolescent Suicide-Attempters Admitted to an Intensive Care Ward. Japanese J Child Adolescent Psychiatry 2004;45:25-34

8. Moscicki. Suicide. The Psychiatric Clinics of North America. Philadelphia: Saunders, 2003:504-513

9. ICDDR,B. Mortality Due to Suicide in Rural Bangladesh. Health and Science Bulletin. 2003;1(5):7-10.

10. Dunner. Current Psychiatric Therapy. Philadelphia: Saunders, 1997:548 
11. Abhaya Indrayan, M.J.Wysocki, Rajeev Kumar, et al. Estimates of the Years of Life lost due to the top nine causes of death in rural areas of major states in India in1995, Nat Med J of India 2002;15:1

12. Kim WJ, Singh T. Trends and dynamics of youth suicides in developing countries. The Lancet 2004; 363, 1090-1091.

13. Government of Kerala 2004 suicides, Kerala Crime Records Bureau, Government of Kerala, Trivandrum.

14. Sanjush B, Manju P, Yesudas KF. Psychiatric diagnosis in attempted suicide. Calicut Medical J 2006; 4(3):e2

15. Gupta.S.C, Singh H. Psychiatric illness in Suicide Attempters. Indian J Psychiatry 1981; 23 (1) 69-74.
16. Galgali RB, Sanjeev R, Ashok MV, et al. Psychiatric Diagnosis of Self-Poisoning Cases a General Hospital Study. Indian J Psychiatry 1998; 40(3): 254-259.

17. Kandamuthan M. Preliminary findings on the Psychosocial factors for attempt of suicide in Kerala. NIMHANS Journal 1998; 1: 261-270.

18. Althaus D, Hegerl U. The evaluation of suicide prevention activities: state of the art. World J Biol Psychiatry 2003; 4(4):156-65.

19. Cheng ATA, Tony H H chen, Chen CC, et al. Psychosocial and psychiatric risk factors for suicide; Case control psychological autopsy study. British Medical J 2000; 177:360-365. 